\title{
Preparation of Steels for SEM Backscatter Electron Imaging: Some Observations of Pearlite, Bainite, and Martensite in Plain Carbon Steels
}

\author{
James H. Steele Jr. Ph.D. Consultant, 2019 Nova Road, Pine, CO 80470
}

The preparation of steels for examination by backscatter electron (BSE) imaging in the SEM can be carried out by electro-polishing samples following a standard metallographic polish [1]. This procedure does not provide optimum contrast for observation via optical microscopy, as does chemical etching. The normal technique applied for examination of microstructure in steels via SEM is to examine chemically etched surfaces using secondary electron imaging (SEI), wherein topography of etched surfaces is observed at high resolution. The observation of microstructural constituents in steels using BSE depends upon the inherent contrast mechanisms, i.e. variation in the backscatter coefficient that occurs with changes in atomic number (Z-contrast), and crystal orientation (channeling contrast). These two contrast mechanisms provide excellent BSE images of pearlite, bainite, and martensite in steels, if the final electro-polishing step does not produce significant surface topography. Examples presented in this paper were electro-polished with $10 \%$ perchloric acid, $80 \%$ methyl alcohol, and 10\% butyl cellosolve in a cold bath of dry ice and alcohol after standard metallographic polishing [2]. The BSE images were obtained with a 4-crystal solid state detector using normal incidence and a $20 \mathrm{KV}$ beam energy.

An example of pearlite in a 1008 billet steel sample is presented in Fig. 1, which shows the Zcontrast between the cementite $\left(\mathrm{Fe}_{3} \mathrm{C}\right)$ and $\alpha$-ferrite (bcc phase) layers. One can also observe cementite layers at a ferrite grain boundary, and channeling contrast exhibited by the different orientations of growth colonies within the pearlite region. There are also indications of substructure (dislocation cells) within the ferrite grains of the hot rolled billet. Pearlite colonies in a transverse section of normalized (air cooled) 1070 steel wire are shown in the micrograph presented in Fig. 2.

The bainitic microstructure in an AMB 16 steel $(0.31 \% \mathrm{C} / 1.75 \% \mathrm{Mn} / 0.03 \% \mathrm{Cu} / 0.3 \% \mathrm{Mo} / 0.1 \% \mathrm{Si})$ that was formed by isothermal transformation in a lead bath at $370^{\circ} \mathrm{C}$ is shown in Fig. 3. The distribution of cementite precipitates within this granular type bainite can be readily observed, as can crystal orientation differences between several of the bainitic packets.

Lath martensite in AMB 16 steel that was quenched in ice brine after holding for $30 \mathrm{sec}$. in a lead bath at $650^{\circ} \mathrm{C}$ is illustrated by the BSE micrograph shown as Fig. 4. Proeutectoid ferrite $(\alpha)$, and the martensite lath structure are readily observed in this micrograph. In this BSE image there is some topographic contrast added to the channeling contrast between the martensitic laths.

Martensitic substructure in an alloy steel $(5 \% \mathrm{Cr} / 5 \% \mathrm{Ni} / 5 \% \mathrm{Si} / 10 \% \mathrm{Mn} / 0.2 \% \mathrm{C})$ that was quenched in ice brine is illustrated in Figures 5 and 6 . The substructure observed in this martensite is a result of channeling contrast between different crystallographic orientations. Excellent resolution (approx. 50nm) is illustrated by the width of the sub-boundaries observed in the BSE micrographs.

References

[1] J.H. Steele Jr., Microsc. Microanal. 8 (Suppl. 2) (2002) 1262.

[2] "Electrolytic Polishing," In ASM Metals Handbook, $8^{\text {th }}$ ed., Vol. 8, (1973) pp. 26-33. 


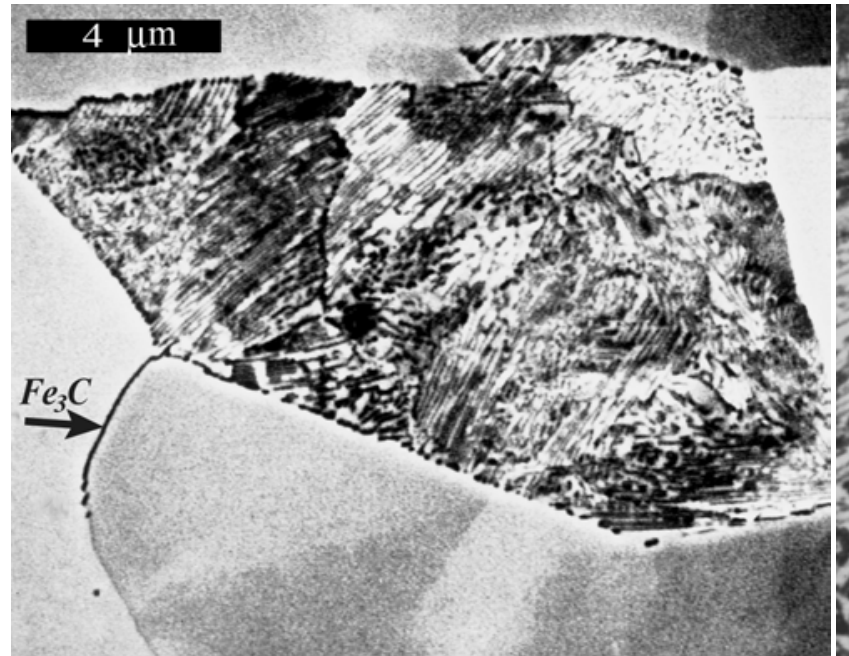

Fig. 1 Pearlite in SAE 1008 Steel Billet.

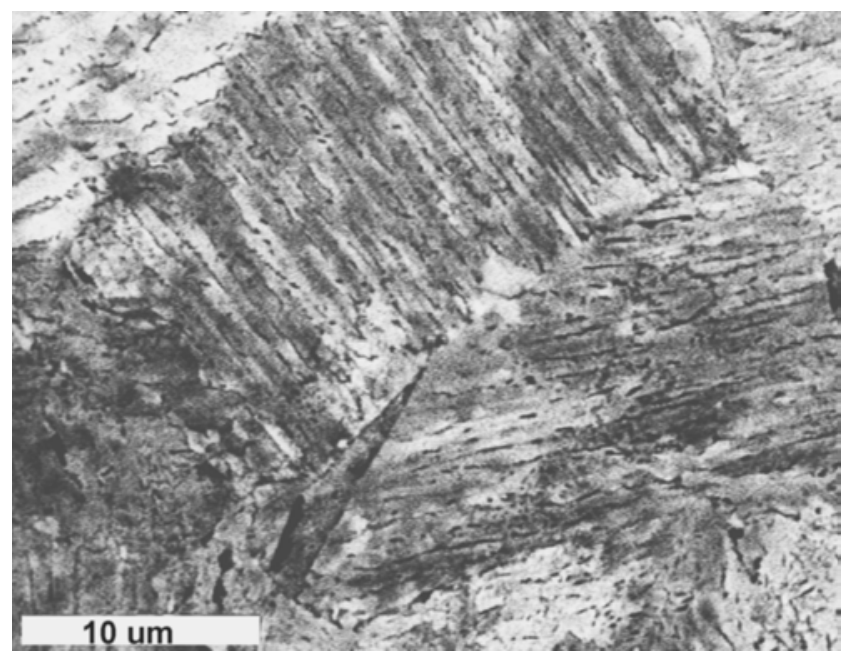

Fig. 3 Bainite in AMB 16 Steel.

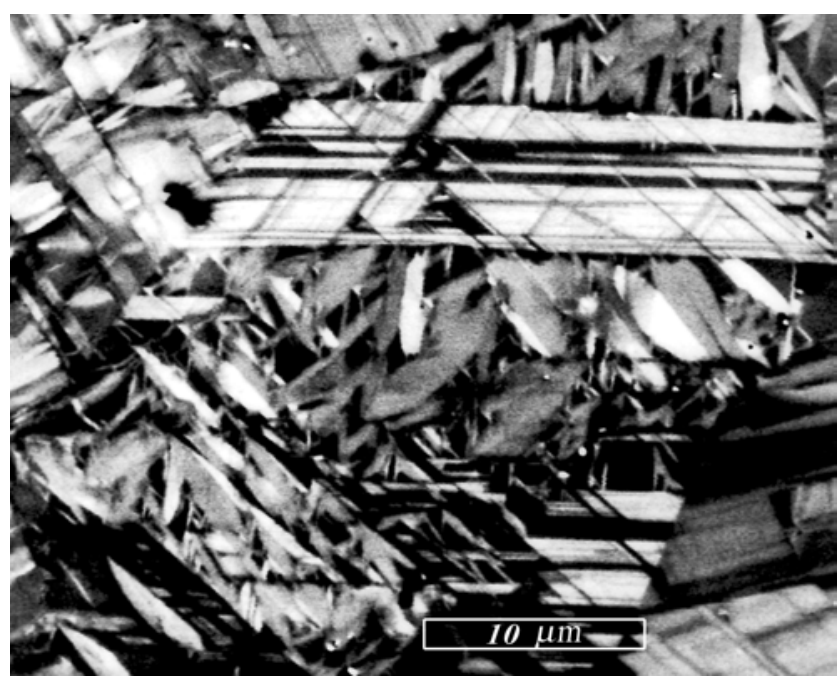

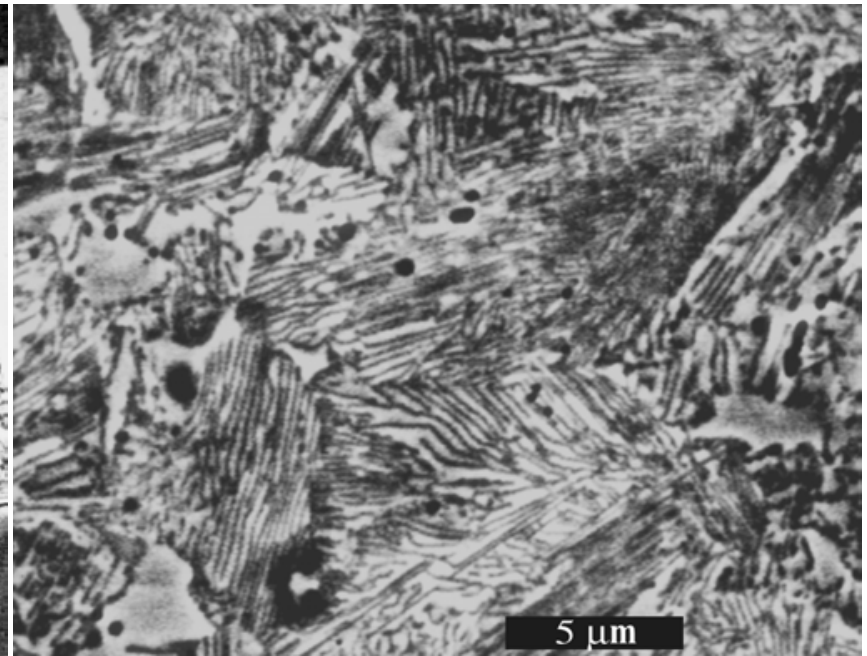

Fig. 2 Pearlite in SAE 1070 Steel wire.

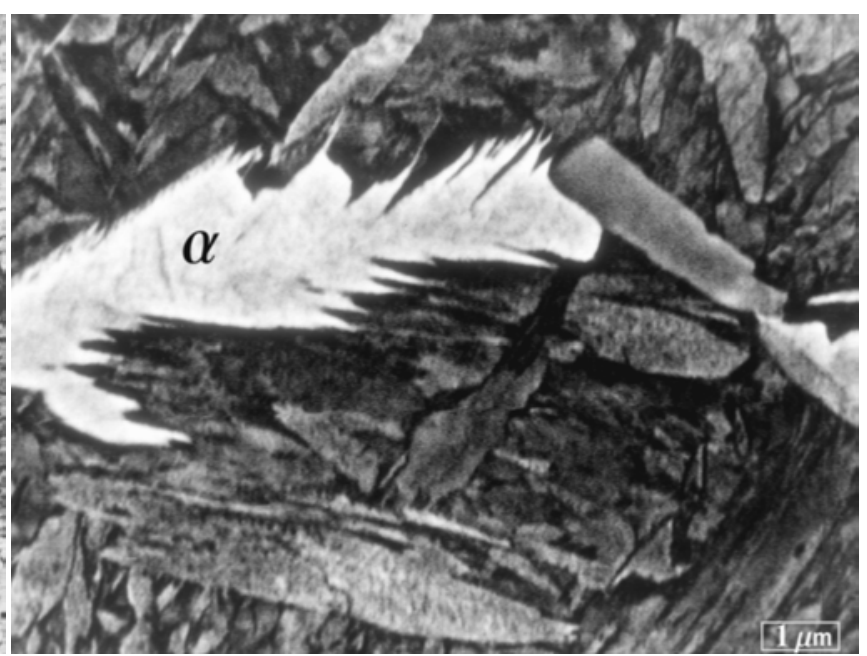

Fig. 4 Lath Martensite in AMB 16 Steel.

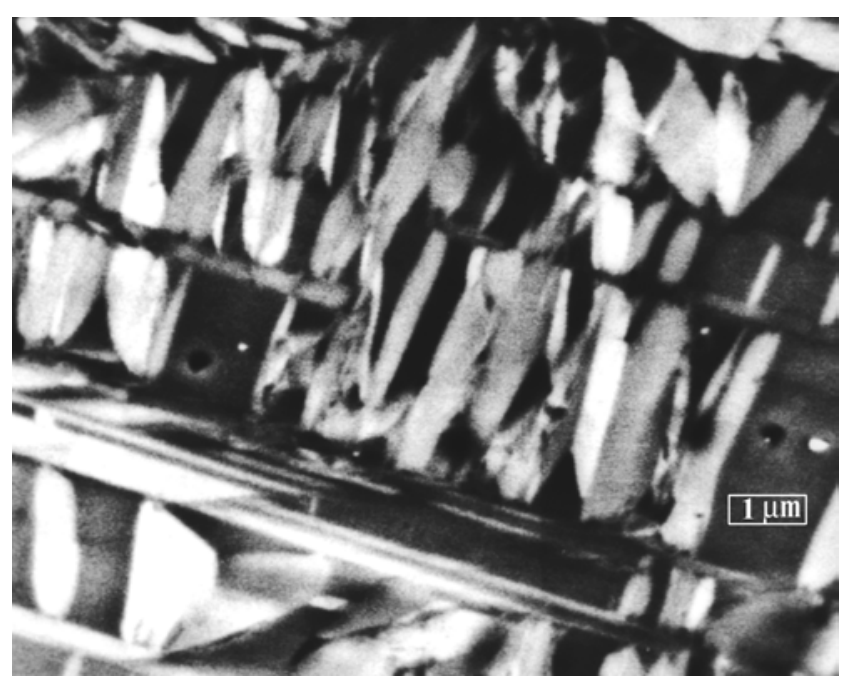

Fig.5 Martensitic substructure in an Alloy Steel. Fig 6. High Mag. BSE Image of Martensite. 